\title{
Preconditioning of skeletal myoblast-based engineered tissue constructs enables functional coupling to myocardium in vivo
}

\author{
Philipp Treskes, PhD, ${ }^{\mathrm{a}, \mathrm{b}, \mathrm{c}}$ Klaus Neef, PhD, ${ }^{\mathrm{a}, \mathrm{b}}$ Sureshkumar Perumal Srinivasan, MSc, ${ }^{\mathrm{a}, \mathrm{b}, \mathrm{c}}$ \\ Marcel Halbach, MD, ${ }^{\mathrm{c}, \mathrm{d}}$ Christof Stamm, MD, ${ }^{\mathrm{e}}$ Douglas Cowan, $\mathrm{PhD},{ }^{\mathrm{f}}$ Maximilian Scherner, MD, \\ Navid Madershahian, MD, ${ }^{\mathrm{a}}$ Thorsten Wittwer, MD, ${ }^{\mathrm{a}}$ Jürgen Hescheler, MD, ${ }^{\mathrm{c}}$ Thorsten Wahlers, MD, ${ }^{\mathrm{a}, \mathrm{b}}$ and \\ Yeong-Hoon Choi, MD ${ }^{\mathrm{a}, \mathrm{b}}$
}

\begin{abstract}
Objective: Skeletal myoblasts fuse to form functional syncytial myotubes as an integral part of the skeletal muscle. During this differentiation process, expression of proteins for mechanical and electrical integration is seized, which is a major drawback for the application of skeletal myoblasts in cardiac regenerative cell therapy, because global heart function depends on intercellular communication.
\end{abstract}

\begin{abstract}
Methods: Mechanically preconditioned engineered tissue constructs containing neonatal mouse skeletal myoblasts were transplanted epicardially. A Y-chromosomal specific polymerase chain reaction (PCR) was undertaken up to 10 weeks after transplantation to confirm the presence of grafted cells. Histologic and electrophysiologic analyses were carried out 1 week after transplantation.
\end{abstract}

\begin{abstract}
Results: Cells within the grafted construct expressed connexin 43 at the interface to the host myocardium, indicating electrical coupling, confirmed by sharp electrode recordings. Analyses of the maximum stimulation frequency $(5.65 \pm 0.37 \mathrm{~Hz})$, conduction velocity $(0.087 \pm 0.011 \mathrm{~m} / \mathrm{s})$ and sensitivity for pharmacologic conduction block $(0.736 \pm 0.080 \mathrm{mM}$ 1-heptanol) revealed effective electrophysiologic coupling between graft and host cells, although significantly less robust than in native myocardial tissue (maximum stimulation frequency, $11.616 \pm 0.238 \mathrm{~Hz}, P<.001$; conduction velocity, $0.300 \pm 0.057 \mathrm{~m} / \mathrm{s}, P<.01$; conduction block, $1.983 \pm 0.077 \mathrm{mM} 1$-heptanol, $P<.001)$.

Conclusions: Although untreated skeletal myoblasts cannot couple to cardiomyocytes, we confirm that mechanical preconditioning enables transplanted skeletal myoblasts to functionally interact with cardiomyocytes in vivo and, thus, reinvigorate the concept of skeletal myoblast-based cardiac cell therapy. (J Thorac Cardiovasc Surg 2015;149:348-56)
\end{abstract}

See related commentary on pages 357-9.

Cardiovascular disease and specifically ischemic heart disease are the most common causes of natural death worldwide. ${ }^{1}$ In cases of massive myocardial infarction

From the Department of Cardiothoracic Surgery, ${ }^{a}$ Heart Center, Center for Molecular Medicine Cologne, ${ }^{\mathrm{b}}$ Institute for Neurophysiology, ${ }^{\mathrm{c}}$ and Department of Internal Medicine III, ${ }^{\mathrm{d}}$ Heart Center, University of Cologne, Cologne, Germany;

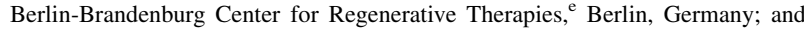
Departments of Anesthesiology and Perioperative and Pain Medicine, ${ }^{\mathrm{f}}$ Children's Hospital Boston and Harvard Medical School, Boston, Mass.

This work was supported by the Center for Molecular Medicine Cologne.

Disclosures: Douglas Cowan has received grant support from the Children's Heart

Foundation and the American Heart Association. Thorsten Wahlers has received lecture fees from Edwards LifeSciences. All other authors have nothing to disclose with regard to commercial support.

P.T. and K.N. contributed equally to this work.

Received for publication June 6, 2014; revisions received Sept 5, 2014; accepted for publication Sept 10, 2014; available ahead of print Oct 22, 2014.

Address for reprints: Yeong-Hoon Choi, MD, Department of Cardiothoracic Surgery, Heart Center of the University of Cologne, Kerpener Strasse 62, 50924 Cologne, Germany (E-mail: yh.choi@uk-koeln.de).

$0022-5223 / \$ 36.00$

Copyright (c) 2015 by The American Association for Thoracic Surgery http://dx.doi.org/10.1016/j.jtcvs.2014.09.034
(MI) and acute heart failure, implantation of ventricular assist devices and ultimately heart transplantation are currently the only therapeutic options available. Endogenous cardiomyocyte regeneration after MI is negligible ${ }^{2}$ and not sufficient to compensate for the detrimental effects of MI on heart function. Thus, the application of cells or tissues to support cardiac regeneration or repair damaged heart muscle is an attractive therapeutic option.

Skeletal myoblasts (SMs) represent an extensively studied progenitor cell type from skeletal muscle. They can be acquired with minimum invasiveness as biopsies from patients regardless of age $^{3}$ and comorbidities ${ }^{4}$ allowing extensive in vitro cell culture expansion. SMs also show remarkable resistance to ischemia ${ }^{5}$ and are committed to a myogenic differentiation. Preclinical cell transplantation studies using SMs have confirmed efficacy for improving postinfarction left ventricular function. ${ }^{6}$ SMs were the first cell type applied in clinical trials on cell-based cardiac regenerative therapies ${ }^{7}$ and have been shown to improve the development of heart function after MI. ${ }^{8}$ However, cases of arrhythmia after intramyocardial transplantation of SMs have been observed., 


$$
\begin{aligned}
& \text { Abbreviations and Acronyms } \\
& \begin{aligned}
\text { AP } & =\text { action potential } \\
\text { bFGF } & =\text { basic fibroblast growth factor } \\
\text { DAPI } & =4^{\prime}, 6 \text {-diamidino-2-phenylindole } \\
\text { DMEM } & =\text { Dulbecco's modified Eagle's medium } \\
\text { EHS } & =\text { embryonic heart slices } \\
\text { ETC } & =\text { engineered tissue construct } \\
\text { FBS } & =\text { fetal bovine serum } \\
\text { MI } & =\text { myocardial infarction } \\
\text { NP } & =\text { nonpreconditioned } \\
\text { P } & =\text { preconditioned } \\
\text { PBS } & =\text { phosphate-buffered saline } \\
\text { PCR } & =\text { polymerase chain reaction } \\
\text { SM } & =\text { skeletal myoblast }
\end{aligned}
\end{aligned}
$$

To address these electrophysiologic incompatibilities between transplanted cells and host myocardium, genetic manipulation of SMs before transplantation have been carried out in animal studies, ${ }^{11,12}$ although they lack potential for clinical translation.

Different methods and platforms for the delivery of cells have been developed for various cell types, with supplemental pharmaceutical agents, and artificial or biological materials. Intramyocardial injection, although the most direct method of delivering cells to the heart, has from low cellular retention in the receiving tissue. ${ }^{13,14}$ However, cell retention, survival, and integration are improved when cells are transplanted within engineered tissue constructs (ETCs) compared with injections as cell suspensions. ${ }^{15,16}$ The application of ETCs allows precise control of cell numbers, shape, size, and structure of the graft with reduced cell loss by washout. ${ }^{17}$

Previously, we have shown that mechanical preconditioning of collagen-based and SM-containing ETCs led to the preservation of gap junction protein expression, which normally subsides during the differentiation of SMs to myotubuli and myofibers. ${ }^{18}$ In addition, we confirmed that mechanical preconditioning led to preservation of the electromechanical competence of SMs, as they coupled to cardiomyocytes in vitro. ${ }^{19}$

The aim of the present study was to confirm electrical coupling between transplanted SM-containing ETCs and host myocardium in vivo by a novel application of the viable heart slice technique. ${ }^{20}$

\section{METHODS}

\section{Cell Isolation}

SMs were isolated as described before. ${ }^{18}$ The resulting primary cells were resuspended in isolation medium, consisting of Ham's F10 medium (Invitrogen, Darmstadt, Germany), 20\% fetal bovine serum (FBS; Invitrogen), $2.5 \mathrm{ng} / \mathrm{mL}$ basic fibroblast growth factor (bFGF; PeproTech, Hamburg, Germany), $0.5 \mu \mathrm{g} / \mathrm{mL}$ Fungizone (Invitrogen), and $1 \%$ penicillin/streptomycin (Invitrogen), transferred to coated $\left(5 \mu \mathrm{g} / \mathrm{cm}^{2}\right.$ collagen type I; Invitrogen) dishes at a density of $10^{5}$ cells $/ \mathrm{cm}^{2}$ and purified by preplating after serial transfers at 1,2,18, and 48 hours. After the last incubation step, nonadherent cells were discarded and the remaining adherent cells were collected, resuspended in growth medium $(40 \%$ Ham's F10 medium, 40\% Dulbecco's modified Eagle's medium (DMEM; Invitrogen), 20\% FBS, $2.5 \mathrm{ng} / \mathrm{mL}$ bFGF, $0.5 \mu \mathrm{g} / \mathrm{mL}$ Fungizone, and $1 \%$ penicillin/streptomycin) and plated on collagen-coated dishes. Cell culture passages were performed at $80 \%$ confluence, including 15 minutes of preplating before transfer. After 1 week of expansion, the cells were used for the fabrication of ETCs.

\section{Engineered Tissue Constructs}

ETCs were prepared as previously published. ${ }^{18,21}$ Briefly, SMs were counted and labeled with Vybrant DiI Cell-Labeling Solution (Invitrogen). The matrix, consisting of isolation medium, collagen (type $\mathrm{I}, 3 \mathrm{mg} / \mathrm{mL}$; Invitrogen) and Geltrex (Invitrogen), was mixed with $5 \times 10^{6} \mathrm{SMs}$, cast into custom-made molds and incubated for 3 days at $37^{\circ} \mathrm{C}$ in $5 \% \mathrm{CO}_{2}$. These molds direct the mechanical strain exerted by polymerization along the axis between the fixed polyester meshes thus generating passive mechanical tension (preconditioned ETCs [P-ETCs]). As a control for the preconditioning effects, the cell matrix mixture was poured directly onto the cell culture dish (nonpreconditioned ETCs [NP-ETCs]; Figure 1). After 3 days, the ETCs were transferred to differentiation medium, consisting of DMEM, $2 \%$ horse serum (PAA Laboratories, Cölbe, Germany), $0.5 \mu \mathrm{g} / \mathrm{mL}$ Fungizone, 1\% penicillin/streptomycin, and incubated for 10 days with medium changed daily.

\section{ETC Transplantation}

Animals received humane care in compliance with the European Convention for the Protection of Vertebrate Animals used for Experimental and Other Scientific Purposes. The local governmental authorities of the State of North Rhine-Westphalia (LANUV) approved all experiments.

Female C57BL/6 mice (6-8 weeks old) were operated on as previously described. ${ }^{22}$ Briefly, after induction of anesthesia (initial, $5 \%$ for maintenance, $1.5 \%$ isoflurane (Deltaselect, Pfullingen, Germany) in an equal mixture of $\mathrm{N}_{2} \mathrm{O}$ and $\mathrm{O}_{2}$ ), the heart was exposed through a left lateral thoracotomy and the middle part of a fully differentiated, labeled ETC (approximately $3 \mathrm{~mm} \times 3 \mathrm{~mm}$ ) was transplanted onto the left ventricle, and held in position using 4 prolene sutures $(8 / 0$; Ethicon, Norderstedt, Germany; Figure 1).

\section{Histochemistry}

Mice were killed, hearts were removed, rinsed, and perfused with phosphate-buffered saline (PBS; Invitrogen). Cryosections of the hearts (10 $\mu \mathrm{m})$ were stained with Masson's trichrome method following the manufacturer's instructions (Sigma-Aldrich). For immunofluorescence staining, cryosections were fixed and permeabilized with $4 \%$ paraformaldehyde, $0.25 \%$ Triton X-100, $0.5 \mathrm{M} \mathrm{NH}_{4} \mathrm{Cl}$ (all Sigma-Aldrich) in PBS and blocked with $5 \%$ bovine serum albumin (Invitrogen) in PBS. The primary and secondary antibodies were diluted in PBS with $1 \%$ bovine serum albumin.

Primary antibodies were antidesmin (GeneTex, Irvine, Calif), anticonnexin 43 (Sigma-Aldrich), antidystrophin and anticardiac troponin I (both Santa Cruz Biotechnology, Santa Cruz, Calif) at concentrations recommended by the manufacturer and detected with species-specific Alexafluor-488- or Alexafluor-568-conjugated secondary antibodies (Invitrogen). Nuclei were stained using 4',6-diamidino-2-phenylindole (DAPI, 1:1000; Invitrogen). Fluorescence microscopy was performed using an Eclipse Ti-U microscope with NIS Elements BR v3.10 software (Nikon, Düsseldorf, Germany).

\section{Y-Chromosomal PCR}

Genomic DNA was prepared from whole hearts using the DNeasy Blood and Tissue kit (Qiagen, Hilden, Germany). Polymerase chain reactions 


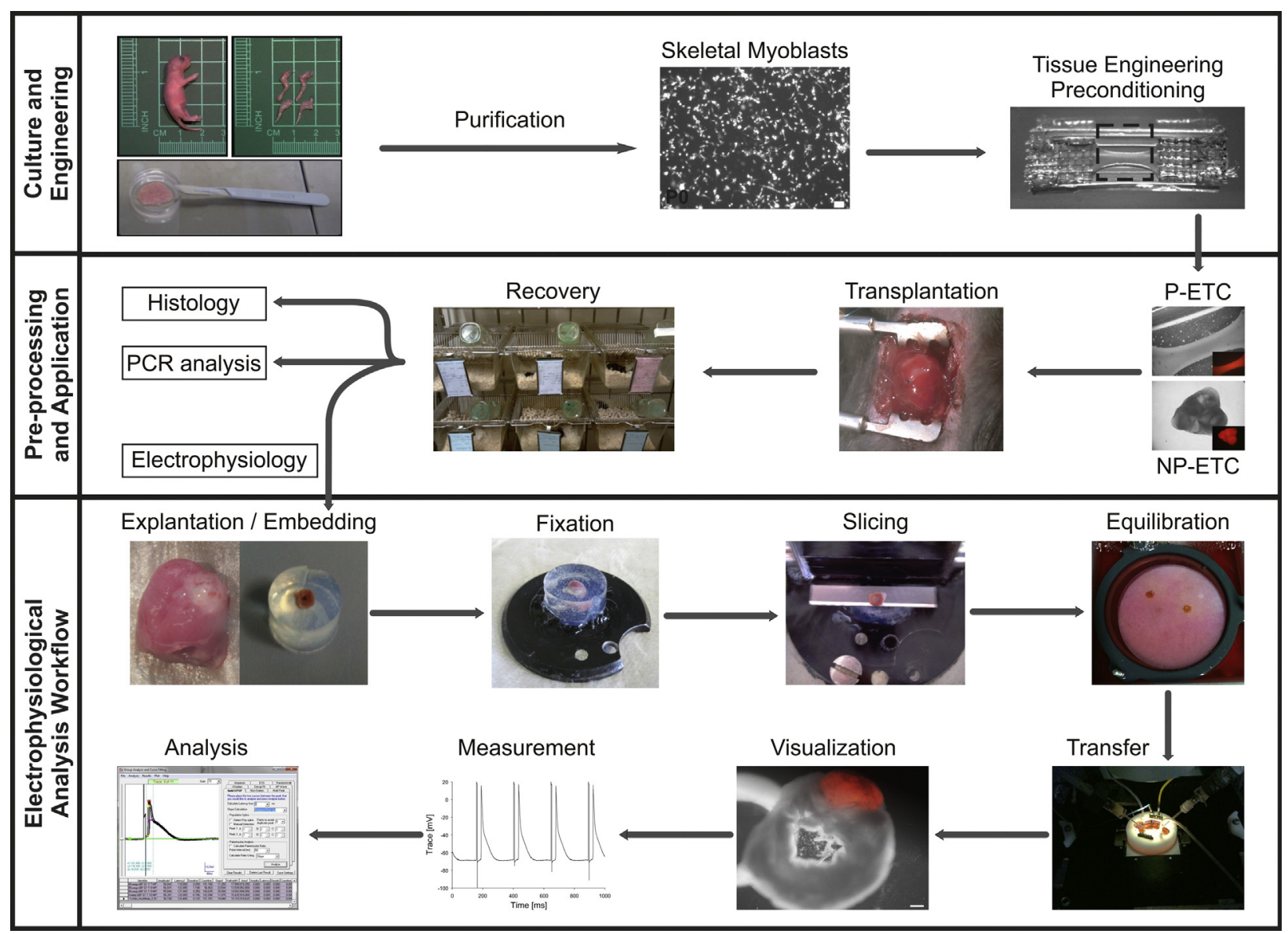

FIGURE 1. Experimental workflow from cell isolation and purification to tissue engineering and functional in vivo analysis of grafted tissue by sharp electrode measurement. Overview of the steps involved in primary cell isolation and processing. After isolation, cells were purified by preplating. The adherent cell population after preplating contained predominantly skeletal myoblasts. Scale represents $100 \mu \mathrm{m}$. These cells were expanded and seeded into a collagen-based matrix and either dropped into a dish as a control or cast into a mold $(3 \mathrm{~cm}$ in length) for passive mechanical preconditioning during polymerization. These preconditioned $(P)$ or nonpreconditioned $(N P)$ engineered tissue constructs $(E T C s)$ were fabricated and prelabeled with DiI, before they were transplanted epicardially to mouse hearts. Animals were then placed in animal holding for recovery. After 1 week, hearts were explanted for various analyses as detailed in the text. For sharp electrode measurements, whole hearts were embedded in a cylinder of agarose and sectioned using a microtome into $200-\mu \mathrm{m}$-thick viable heart slices. Slices were equilibrated in medium and transferred to a sharp electrode measurement setup. Responsive slices carrying parts of the grafted ETC (scale represents $100 \mu \mathrm{m}$ ) were measured and analyzed. PCR, Polymerase chain reaction.

(PCR) to detect Y-chromosomal DNA were set up in a $25-\mu \mathrm{L}$ reaction using 100 ng genomic DNA, $1 \mu \mathrm{L}$ of Taq polymerase (TrueStart Taq Polymerase, Fermentas, St. Leon-Rot, Germany), and $0.2 \mu \mathrm{M}$ primers (specific to the murine Y-chromosomal SRY locus, ${ }^{23}$ forward $5^{\prime}$-TGGGACTGGTGA CAATTGTC-3' and 5'-GAGTACAGGTGTGCAGCTCT-3'; synthesized by Invitrogen) resulting in a product with 402 base pairs. PCR was performed on a Veriti Thermal Cycler (Applied Biosystems, Foster City, Calif) under the following reaction conditions: $95^{\circ} \mathrm{C}$ for 4 minutes, followed by 35 cycles of $95^{\circ} \mathrm{C}$ for 35 seconds, $64^{\circ} \mathrm{C}$ for 1 minute, and $72^{\circ} \mathrm{C}$ for 1 minute, followed by $72^{\circ} \mathrm{C}$ for 5 minutes.

\section{Flow Cytometry}

For flow cytometric validation of ETC viability after 1 week, hearts were explanted and the graft was carefully removed. It was subsequently digested by incubation in a solution of $0.2 \%$ collagenase type IV (Invitrogen), $2.4 \mathrm{IU} / \mathrm{mL}$ dispase (Invitrogen), and $3 \mathrm{mM} \mathrm{CaCl}_{2}$ (Merck, Darmstadt, Germany) in PBS for 30 minutes at $37^{\circ} \mathrm{C}$ before staining with propidium iodide solution $(1 \mathrm{mg} / \mathrm{mL}$; Invitrogen) following the manufacturer's protocol. Measurements were performed using a FACSCalibur flow cytometer (BD Biosciences, Heidelberg, Germany) with a minimum of 10,000 viable cells. Analysis was performed with CellQuest Pro 6 software (BD Biosciences).

\section{Electrophysiologic Analysis}

Hearts were explanted 1 week after construct transplantation and $200-\mu \mathrm{m}$-thick vital heart slices were prepared as described previously. ${ }^{20}$ The heart slices were assessed electrophysiologically in DMEM, preoxygenated with carbogen $\left(95 \% \mathrm{O}_{2}\right.$ and $\left.5 \% \mathrm{CO}_{2}\right)$ at $37^{\circ} \mathrm{C}$, under direct visualization using an Axiovert 200 fluorescence microscope (Zeiss, Oberkochen, Germany; Figure 1). Slices were tested for successful contraction on electrical stimulation before the measurements.

Sharp electrode measurements were performed in host myocardium (recording electrode) with microelectrodes $(20-40 \mathrm{M} \Omega, 3 \mathrm{M} \mathrm{KCl}$; Sigma-Aldrich) fabricated from filamented borosilicate glass capillaries (WPI, Sarasota, Fla; Figure 1). The impulse propagation and coupling characteristics between grafted and host tissue were assessed by stimulating the vital heart slice with a second microelectrode. The stimulation electrode was placed in the grafted tissue and the minimum 

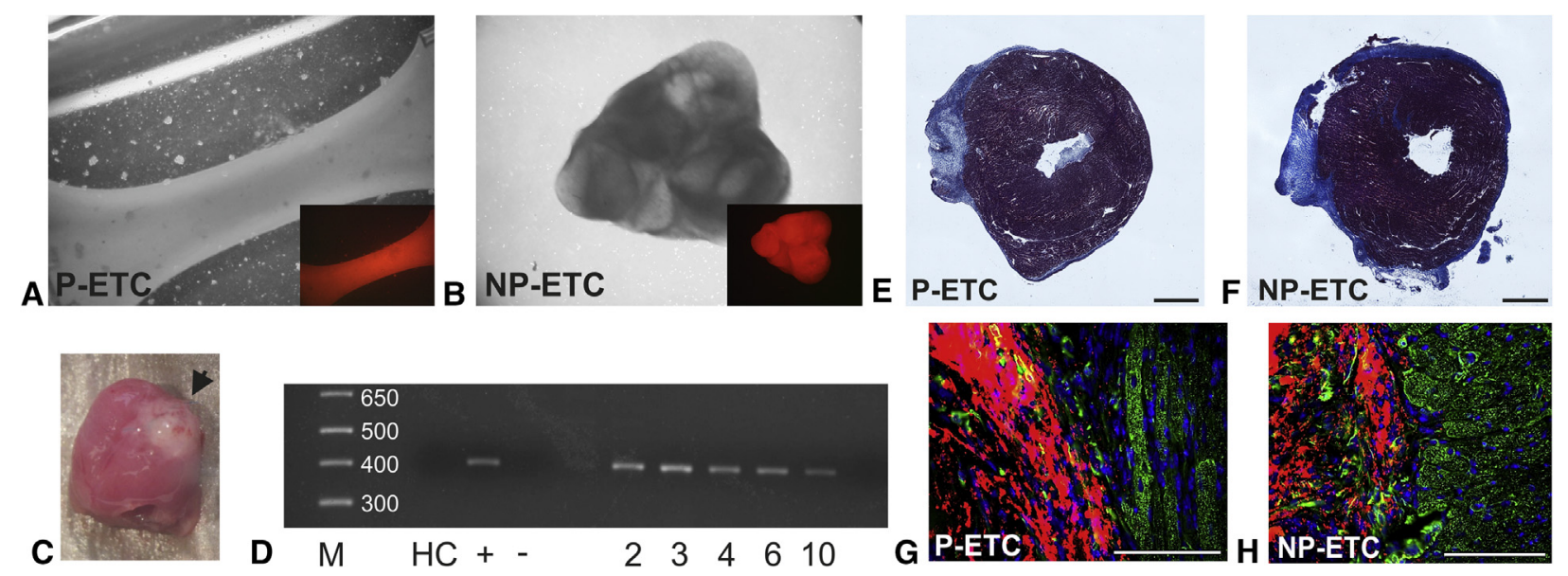

FIGURE 2. Persistence and integrity of engineered tissue constructs $(E T C)$ transplanted heart sections. A and B, Preconditioned $(P)$ or nonpreconditioned $(N P)$ ETCs, fabricated and prelabeled with DiI (inserts, $r e d$ ) before transplantation. C, Representative microphotograph of an explanted heart 1 week after transplantation of a P-ETC (arrow). D, Polymerase chain reaction detection of the mouse Y-chromosome-specific SRY gene performed on whole heart lysates of P-ETC transplanted mice 2, 3, 4, 6, and 10 weeks after transplantation versus a control without genetic material (handling control [HC]), male heart lysate as a positive control (+), and a female C57BL/6 heart lysate as a negative control (-). M is a molecular weight indicator allowing the detection of the 402-bp-long product (as indicated, the region of interest on the gel between 300 and 650 bp is shown here). E and F, Full section of a P-ETC (E) or NP-ETC (F) transplanted heart 1 week after transplantation, demonstrating the high content of extracellular matrix proteins (blue) of the graft by Masson's trichrome staining (scale represents $1 \mathrm{~mm}$ ). G and H, Immunofluorescent staining of hearts sectioned 1 week after transplantation of P-ETC (G) and NP-ETC (H) showing DiI staining (red) of skeletal myoblasts and expression of desmin (green). Scale represents $100 \mu \mathrm{m}$.

voltage (minStim) for generating myocardial action potentials (APs) was established. Subsequent stimulation was performed at (minStim $+10 \%)$ to account for fluctuations in sample-to-electrode resistance. MinStim was reestablished after the stimulation electrode was moved. Next, the maximum frequency of 1:1 conductivity in ETC stimulation versus host stimulation was assessed by applying stimulation at frequencies in the range of 2 to $20 \mathrm{~Hz}$. Conduction velocity was calculated by measuring the time between the stimulation peak and the AP upstroke at a frequency of $2 \mathrm{~Hz}$ against the distance between stimulation and the recording electrode.

Pharmacologic inactivation of gap junctions was then performed with perfusion halted by titration of 1-heptanol (Sigma-Aldrich; $50 \mathrm{mM}$ stock solution, $10-\mu \mathrm{L}$ increments) until stimulation of the grafted tissue at 2 or $4 \mathrm{~Hz}$ failed to generate myocardial APs. At this blocking concentration, the stimulation electrode was moved to the host tissue to assess host conductivity. The stimulation electrode was then moved back to the graft tissue, after which washout was started by reactivating the perfusion to test the reversibility of the observed inhibition.

Signals were amplified using a SEC-10LX amplifier (npi electronic, Tamm, Germany) and recorded with Pulse software (HEKA, Lambrecht, Germany). Data were analyzed offline using Mini Analysis software v6.0.3 (Synaptosoft, Fort Lee, NJ; Figure 1).

\section{Statistical Analysis}

Data are presented as the mean \pm standard error of the mean unless stated otherwise. Statistical analysis was performed using SigmaStat 4 software (Systat Software GmbH, Erkrath, Germany). Two group comparisons were performed applying the Student $t$ test for unpaired samples. Multiple groups were compared using one-way analysis of variance followed by the post hoc Bonferroni test for multiple comparisons.

\section{RESULTS}

Survival, Retention, and Integration of ETC Cells

Both types of epicardially transplanted ETCs, P-ETCs (Figure 2, $A$ ) and NP-ETCs (Figure 2, B) could be identified macroscopically on explanted hearts 1 week after the operation (Figure 2, C). Detection of transplanted cells by PCR confirmed their presence in lysates from whole hearts up to 10 weeks after transplantation (Figure 2, D). Densitometric analysis, normalized to the 2-week band revealed an initial decrease of around $30 \%$ after 4 weeks up to a decrease of $70 \%$ by week 10.

The epicardial localization of the ETCs was confirmed histologically (Figure 2, $E$ and $F$ ). Immunofluorescent staining confirmed the presence of grafted cells by their DiI labeling in both P-ETC (Figure 2, $G$ ) and NP-ETC (Figure 2, $H$ ) transplanted heart sections. Furthermore, the viability of the grafted tissue and its tight physical interaction with the host tissue were confirmed by desmin and DAPI staining. Flow cytometric assessment revealed viability of $99.16 \% \pm 0.48 \%(n=5)$ of the cells within the ETC 1 week after transplantation (data not shown).

Punctuate desmin (Figure 3, $A$ and $B$ ) and dystrophin (Figure 3, $C$ and $D$ ) staining highlighted the presence of both markers in the grafted tissues, with stronger expression in grafted P-ETCs. Staining for connexin 43 revealed typical polar expression between neighboring cells in the graft-to-host interface in P-ETC (Figure 3,E), but not in NP-ETC transplanted hearts (Figure 3,F). Such focal expression patterns were also clearly visible in the host myocardium, but not within the ETCs. Note here also the absence of anticardiac troponin I staining in either type of grafted tissue. 

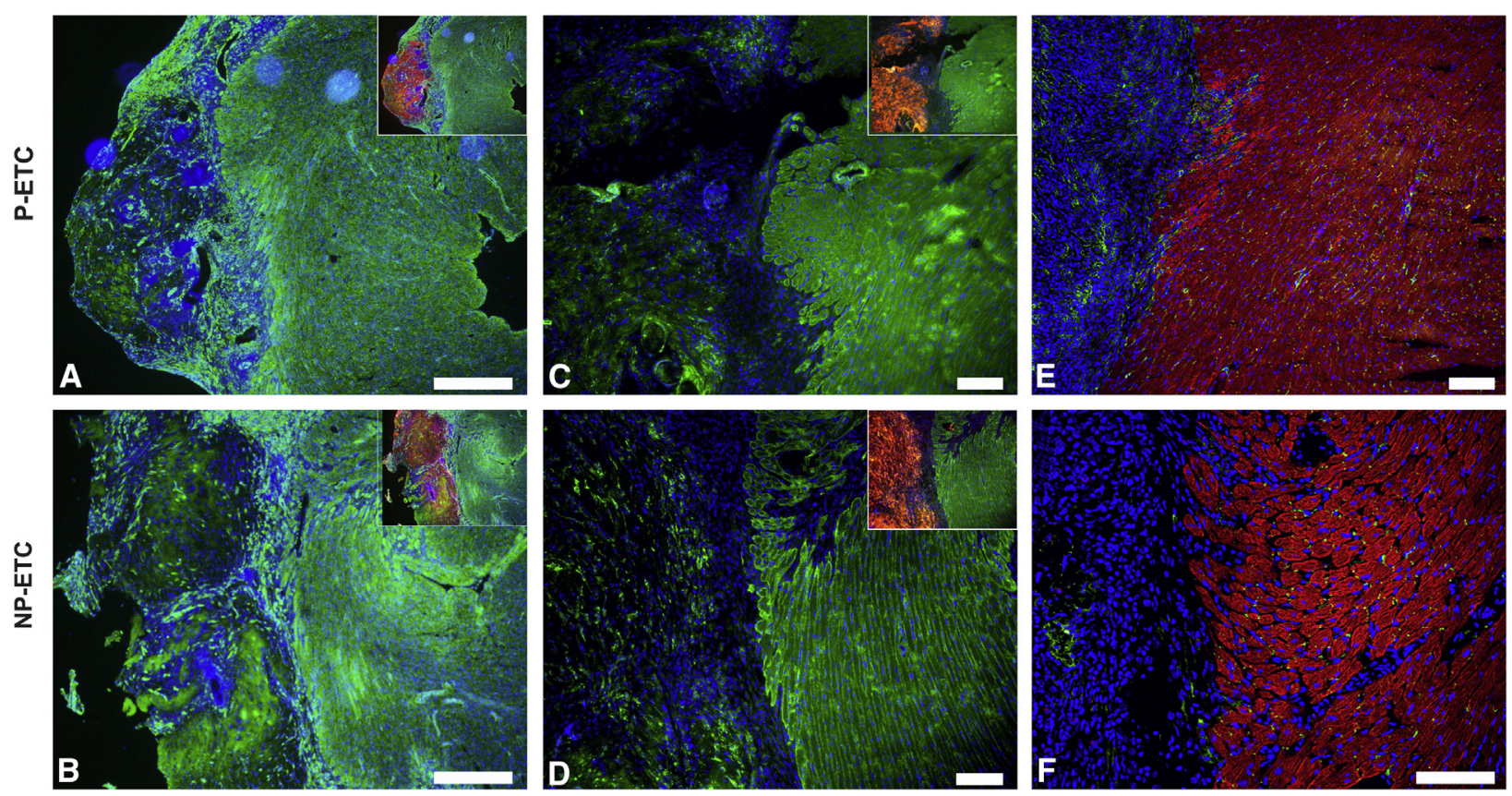

FIGURE 3. Histologic analysis of engineered tissue construct (ETC) transplanted heart sections. Parallel sections from explanted hearts 1 week after construct transplantation stained against various structural and functional maturation markers (4',6-diamidino-2-phenylindole in blue). Desmin (green) stainings of preconditioned $(P)$-ETC (A) and nonpreconditioned (NP)-ETC (B) grafted heart sections show pronounced desmin expression in the graft-to-host border zone, indicating the formation of young myoblasts (inserts display the same pictures with DiI fluorescence overlayed). Scale bars represent $500 \mu \mathrm{m}$. Dystrophin (green) stainings of P-ETC (C) and NP-ETC (D) grafted heart sections show strongest expression of dystrophin toward the core of the graft, indicating advancing functional maturation (inserts display the same pictures with DiI fluorescence overlayed). Scale bars represent $100 \mu \mathrm{m}$. Double staining of P-ETC (E) and NP-ETC (F) grafted heart sections against connexin 43 ( green) and cardiac troponin I (red) shows ordered cardiac troponin I expression in the host tissue in both sections, which is absent in the ETC region. Furthermore, stronger connexin 43 expression organized in foci between the graft and host tissue was present in P-ETC grafted hearts compared with NP-ETC grafted hearts. Scale represents $100 \mu \mathrm{m}$.

\section{Electrophysiologic Assessment of Functional Integration}

In a separate set of animals, hearts were excised 1 week after surgery and used for the preparation of viable slices, resulting in at least 3 slices per heart incorporating grafted tissue. Point stimulation was performed either in the graft (S1) or the host tissue (S2) with equal distance from the point of measurement within the host myocardium $(\mathrm{M}$; Figure 4, $A$ and $B$ ).

In the case of P-ETC transplanted hearts, APs could be generated successfully in the myocardium (M), when stimulation was carried out in the graft (S1), and they were able to override the irregular APs from spontaneous electrophysiologic activity in the heart slice (Figure 4, C). In contrast, stimulation in the grafted tissue of NP-ETC transplanted heart slices using equal conditions did not lead to entrainment of spontaneous AP generation in the host myocardium (Figure 4, D).

The delay between P-ETC stimulation and AP generation was significantly larger compared with stimulation from the myocardium (S2) at equal distance (Figure 4, E). This conduction delay averaged $22.842 \pm 2.520$ milliseconds at $\mathrm{S} 1$ stimulation in the case of P-ETC transplanted heart slices versus $6.962 \pm 0.862$ milliseconds at $\mathrm{S} 2$ stimulation
$(P<.001)$, resulting in a mean conduction velocity of $0.087 \pm 0.011 \mathrm{~m} / \mathrm{s}(\mathrm{n}=5$ animals, $\mathrm{n}=12$ recordings; Figure $4, F)$ at $\mathrm{S} 1$ stimulation versus $0.300 \pm 0.057 \mathrm{~m} / \mathrm{s}$ ( $\mathrm{n}=9$ animals, $\mathrm{n}=19$ recordings) at $\mathrm{S} 2$ stimulation $(P<.01)$. Myocardial APs from stimulation at S1 had a slightly different shape characterized by lower amplitudes, with a flattening of the downstroke and a slower upstroke, although not reaching statistical significance compared with stimulation from S2 (Table 1).

\section{Maximum Capture Frequency}

The quality of electrical coupling between P-ETC and host myocardium was assessed by determination of the maximum capture frequency. In P-ETC grafted heart slices, the maximum capture was $8 \mathrm{~Hz}$ (Figure $5, A$ ) averaging $5.650 \pm 0.369 \mathrm{~Hz}$ ( 29 recordings). When exceeding $8 \mathrm{~Hz}$, graft-to host conduction occurred at a ratio of $2: 1$ (Figure 5, B), whereas the maximum capture rate under direct myocardial stimulation was $11.616 \pm 0.238 \mathrm{~Hz}$ $(P<.001, \mathrm{n}=15$ recordings; Figure 5, $C$ and $D)$.

\section{Conduction Block}

Pharmacologic studies were performed to verify any differences in graft-to-host versus host-to-host coupling 

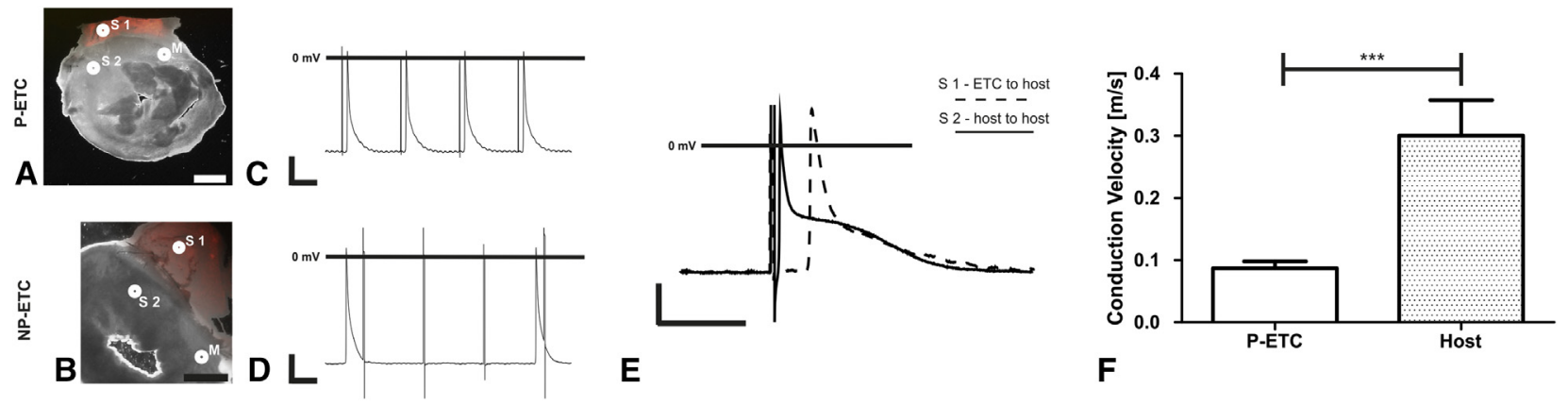

FIGURE 4. Electrophysiologic examination of viable engineered tissue construct $(E T C)$ transplanted heart slices. A and B, Microphotograph of a preconditioned $(P)$-ETC $(\mathrm{A})$ or nonpreconditioned $(N P)$-ETC $(\mathrm{B})$ transplanted viable heart slice 1 week after surgery as seen during measurement. Overlay of phase contract and fluorescent images displaying the electrode positions for ETC stimulation (S1) and host stimulation (S2) as well as the position of the recording electrode in the host myocardium $(M)$. Scale bar represents $1 \mathrm{~mm}$. C and D, Assessment of ETC to host coupling. In P-ETCs (C), myocardial action potentials are generated through ETC stimulation, whereas NP-ETC stimulation (D) is unsuccessful in entraining spontaneous host myocardial activity. E, Representative overlay of myocardial action potentials evoked by unipolar stimulation in P-ETC transplanted heart sections at (S1) and the host (S2) highlighting the difference in delay between stimulation and myocardial action potential generation at similar electrode distances. Scale represents 100 milliseconds (x-axis), $20 \mathrm{mV}$ (y-axis). F, Graphical representation of calculated conduction velocity displaying significantly lower velocity of P-ETC to host conduction (P-ETC) than direct intramyocardial stimulation (Host). $* * * P<.001$.

and assess the presence of field-stimulation effects. The gap junction blocker, 1-heptanol, was added by titration until stimulation in the P-ETC (Figure 5, E) was no longer able to generate APs in the host. We found that, at this blocking concentration $(0.736 \pm 0.080 \mathrm{mM}, \mathrm{n}=12$ recordings; Figure 5, F), the stimulation electrode was moved, and direct stimulation of the host was performed. Moreover, at this concentration, stimulation in the host tissue was still effective (Figure 5, G), but not at higher concentrations exceeding $1.983 \pm 0.077 \mathrm{mM}(P<.001, \mathrm{n}=19$ recordings; Figure $5, H$ ). In all cases, the 1-heptanol effect was completely reversible.

\section{DISCUSSION}

The rationale of this study was to evaluate the potential for effective electrophysiologic coupling of SM-based ETCs to native myocardium in a murine model. The cells within the ETCs were exposed to longitudinal mechanical

TABLE 1. Parameter comparison between host and P-ETC evoked action potentials

\begin{tabular}{lrr}
\hline & \multicolumn{2}{c}{ P-ETC } \\
\cline { 2 - 3 } & S1: ETC to host & S2: host to host \\
\hline MDP $(\mathrm{mV})$ & $-75.1 \pm 1.5$ & $-77.2 \pm 2.4$ \\
Amplitude $(\mathrm{mV})$ & $77.7 \pm 2.2$ & $84.5 \pm 2.4$ \\
$\mathrm{~V}_{\max }(\mathrm{V} / \mathrm{s})$ & $103.3 \pm 7.6$ & $124.9 \pm 9.4$ \\
$\mathrm{APD}_{50}(\mathrm{~ms})$ & $10.0 \pm 0.8$ & $7.4 \pm 0.7$ \\
$\mathrm{APD}_{90}(\mathrm{~ms})$ & $69.4 \pm 3.4$ & $66.6 \pm 3.2$ \\
$\mathrm{APD}_{50 / 90}(\%)$ & $14.5 \pm 1.0$ & $11.1 \pm 0.9$ \\
\hline$P$ - $E T C$, Preconditioned engineered tissue constructs; $M D P$, maximum diastolic \\
potential; $V_{\max }$, maximum upstroke velocity; $A P D_{50}$, action potential duration at \\
$50 \%$ of repolarization; $A P D_{90}$, action potential duration at $90 \%$ of repolarization; \\
$A P D_{50 / 90}$, ratio of $\mathrm{APD}_{50} / \mathrm{APD}_{90}$.
\end{tabular}

strain, which developed from polymerization of the matrix components during the fabrication of the ETCs. Mechanical forces on cells can directly alter cellular activity to an extent that protein expression is induced along the axis of mechanical force. ${ }^{18}$ In this context, we have demonstrated that the application of passive mechanical stimulation results in preservation of connexin 43 expression, essential for intercellular electrophysiologic communication, and thus for potential electrophysiologic coupling to myocardial tissue. ${ }^{18,21}$

Our in vivo findings demonstrated the feasibility of epicardial transplantation of ETCs Constructs were macroscopically detectable after explantation (Figure 2, $C)$, and grafted cells were present for up to 10 weeks (Figure 2,D). This qualitative assessment indicated a reduction in cell numbers during long-term exposure of the grafts in vivo.

Given that we are looking at the effects of the cells after 1 week, the decline in viability was not substantial when discussing and evaluating our results. This is corroborated by quantification of the viability of our ETCs after explantation via negative exclusion propidium iodidebased flow cytometric analysis. Furthermore, both ETC types remained structurally intact in vivo (Figure 2, $E$ and $F$ ) and histologic analyses confirmed not only the presence of the grafted cells by their DiI labeling but also their viability and a tight physical connection between the graft and the host tissue (Figure 2, $G$ and $H$ ).

We assessed the structural maturity of the grafted cells by immunohistochemical staining against desmin and dystrophin. Desmin is a muscle-specific intermediate filament protein and an early myogenic marker, ${ }^{24}$ whereas dystrophin mechanically interconnects cells and 

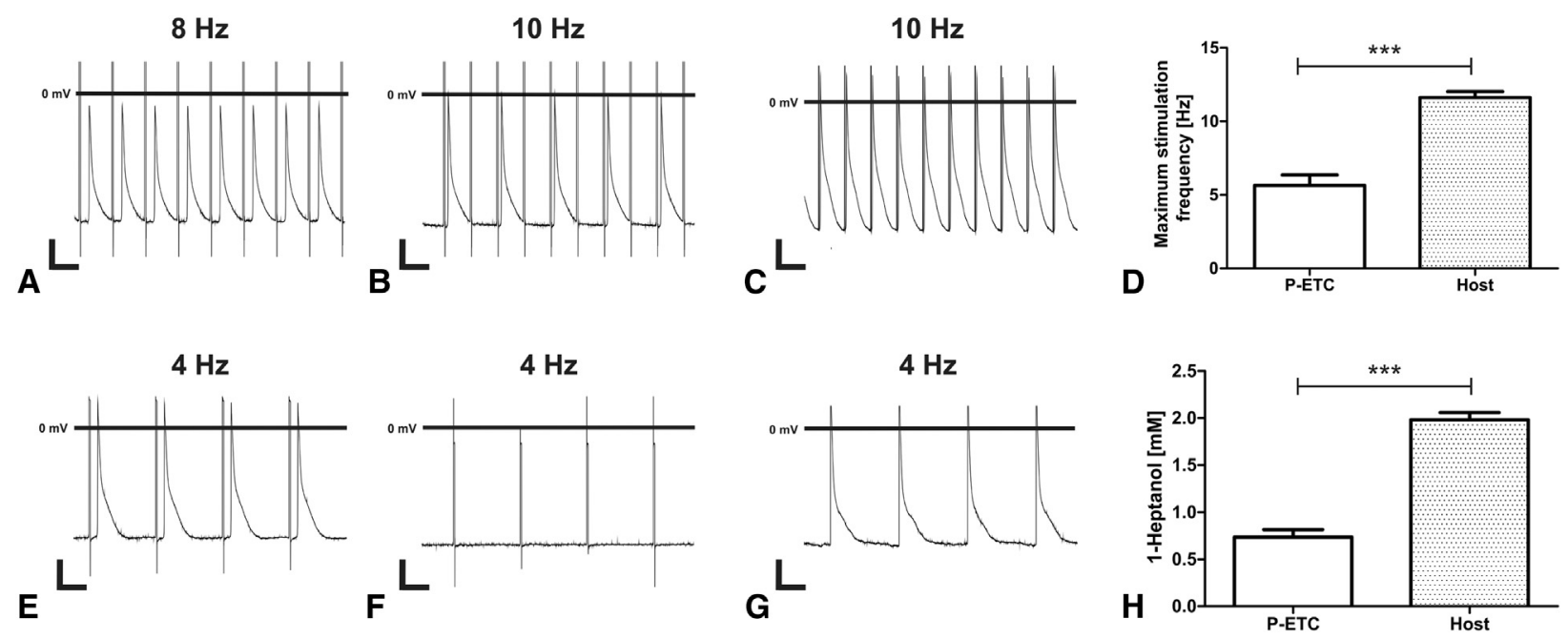

FIGURE 5. Assessment of coupling quality between grafted preconditioned $(P)$ engineered tissue constructs and host myocardium. A-D, Assessment of the maximum frequency of $1: 1$ generation of action potentials. A, Induction of myocardial action potential generation followed stimulation in the P-engineered tissue construct (ETC) up to $8 \mathrm{~Hz}$, but shows a 2:1 conduction block under stimulation at $10 \mathrm{~Hz}$ (B), whereas it follows $10 \mathrm{~Hz}$ stimulation of the host (C). D, Average maximum stimulation frequency from P-ETC or host for myocardial action potential generation without conduction blocks. E-H, Assessment of the robustness of electrophysiologic coupling by pharmacologic inactivation of gap junctions. Myocardial action potentials were generated through P-ETC stimulation at $4 \mathrm{~Hz}(\mathrm{E})$. Application of 1-heptanol led to a block of conduction between graft and host (F), which did not influence conduction in the host tissue, as shown by direct intramyocardial stimulation of the host (G). H, Average 1-heptanol concentrations for blocking myocardial action potential generation through P-ETC or host stimulation. Scales represent 100 milliseconds (x-axis) and $20 \mathrm{mV}$ (y-axis); $* * * P<.001$.

the extracellular matrix, which is characteristic for developmentally mature muscle cells. ${ }^{25}$ Immunohistochemical analyses showed robust expression of both markers irrespective of preconditioning (Figure 3, A-D), suggesting potential for either graft type to provide functional mechanical action and interaction. In agreement with our previous in vitro coupling studies, ${ }^{19}$ there is an apparent difference in the level of expression of both markers between transplanted P-ETCs and NP-ETCs. This emphasizes the inability of NP-ETCs to provide mechanical responses to stimulation in vitro, which was further confirmed by stimulating viable heart slices carrying either type of graft ex vivo (data not shown).

Immunostaining of either P-ETC or NP-ETC transplanted heart sections revealed characteristic focal expression of connexin 43 in the host myocardial tissue (Figure 3, E and $F$ ). However, foci of expression in the graft-to-host interface were however predominantly found in P-ETC transplanted heart sections (Figure 3,E), suggestive of a heightened potential for electrophysiologic coupling between host myocardium and transplanted P-ETCs. The former finding and the apparent presence of connexin 43 in the cytoplasma of grafted cells is corroborated by the quantitative data generated in our previous in vitro ${ }^{19}$ and in vivo ${ }^{21}$ studies.

Although our previous in vivo work provided proof of principle of the cells for electrical coupling, it did not address the quality and characteristics of this coupling in detail. Accordingly, in the present study, the competence for functional in vivo coupling was assessed by electrophysiologic analyses performed on viable heart slices (Figure 4). The viable heart slice technique, in contrast to the previously used Langendorff perfusion model, allows for consideration of graft-to-host conduction, in isolation of global heart conduction, and enables pharmacologic studies of coupling.

The propagation characteristics of myocardial APs were assessed after host or graft stimulation, revealing a lower velocity of conduction between P-ETC and the host, compared with native myocardial conduction (Figure 4, E and $F$ ). In agreement with our previous in vitro studies, ${ }^{19}$ myocardial APs could not be evoked by graft stimulation in NP-ETC transplanted hearts (Figure 4, D). The conduction velocity within the murine myocardium is proportional to the number of functional gap junctions, ${ }^{26}$ mainly formed by connexin 43 proteins. ${ }^{27,28}$ Accordingly, the somewhat sparse focal expression of connexin 43 seen in histologic sections correlates with the confirmed electrophysiologic graft-to-host coupling, and the fact that this coupling is of lower strength than native myocardial coupling.

Areas of slow or blocked conduction have been shown to lead to adverse current flow and consequentially arrhythmia, as observed for cardiac transplantations of SM suspensions ${ }^{29}$ as well as other cells with limited electrophysiologic capabilities (eg, mesenchymal stem 
cells) ${ }^{30}$ Conduction velocities were lower between the graft and the host in P-ETC transplanted hearts; nonsignificant differences were evident between graft- and host-evoked myocardial APs (Table 1) with very low peri- and postoperative mortality rates. These data suggest no adverse influence of grafted tissues on host myocardial function.

To further characterize the quality of the established electrical conduction, the maximum stimulation frequency that resulted in a stable AP generation was determined. ${ }^{19,31}$ This maximum capture frequency from stimulation within the graft (Figure 5, $A$ and $D$ ) was lower than in native heart tissue, but within the physiologic range of adult mice heart rates. ${ }^{32}$ Stimulation above the capture frequency resulted in 2:1 conduction (Figure 5, B). This functional conduction block occurred regularly between successful AP generations. Because the resting membrane potential was always reached after every AP and before the next stimulation peak, we can conclude that such failures in conduction were not caused by incomplete repolarization of the membrane in host tissue. This suggests insufficient electrical propagation between graft and host rather than refractoriness as the cause of conduction blocks.

Furthermore, to verify that the stimulation was propagated from graft to host (and was not caused by field-stimulation effects), we titrated 1-heptanol onto viable heart slices under stimulation (Figure 5, E-H). Heptanol blocks the intercellular electrophysiologic conductance between cells in both cardiac and skeletal muscle tissue in a dose-dependent manner ${ }^{33}$ by reversibly inactivating gap junctions. Because the presence and quality of electrical conduction depends on the level of connexin 43 expression, the sensitivity to conduction block by 1-heptanol is directly correlated to the robustness of the electrophysiologic connection between cells.

The graft-to-host conduction in P-ETC grafted hearts declined continuously as the 1-heptanol concentration was increased (data not shown), and ultimately resulted in conduction block (Figure 5, F). Critically, at this blocking concentration, the host-to-host conduction in the same experiment was not blocked, as we confirmed by moving the stimulation electrode to the host tissue (Figure 5, G).

Comparison of the present study with our in vitro study ${ }^{19}$ confirmed there was correlation between differentiation status and electrophysiologic competence. Given the previous study used embryonic heart slices (EHSs) that were not fully mature, their electrophysiologic capabilities were most likely lower than adult myocardial tissue. The maximum stimulation frequency in EHSs averaged $10.6 \pm 1.6 \mathrm{~Hz}$ (average \pm standard deviation), which is not significantly different from the values measured in viable heart slices from adult myocardial tissue $(11.6 \pm 0.4 \mathrm{~Hz})$. However, the conduction velocity $(0.10 \pm 0.05 \mathrm{~m} / \mathrm{s})$ and 1-heptanol blocking concentration $(0.93 \pm 0.15 \mathrm{mM})$ were significantly lower than the values measured in adult host tissue $(0.30 \pm 0.18 \mathrm{~m} / \mathrm{s}$ and $1.98 \pm 0.34 \mathrm{mM}$, respectively). These observations essentially confirm that the electrophysiologic maturation of embryonic heart tissue is incomplete and reveal that the grafted P-ETCs show clear signs of electrical maturation in vivo. Comparing conduction velocity and 1-heptanol blocking concentrations of EHS versus P-ETC in vivo indicated no significant difference.

This study demonstrates both electrophysiologic competence of preconditioned SMs and their electrophysiologic compatibility with myocardial tissue, together with a functional maturation potential in vivo. Thus far, this essential prerequisite for SM-based myocardial therapies was disputed ${ }^{29}$ and had only been shown for transgenic $\mathrm{SM},{ }^{11,34}$ with limited clinical applicability. Further enhancement of functional efficacy, particularly in terms of long-term therapeutic benefit, will ultimately rely on functional electromechanical integration of the graft into the host tissue.

The use of a clinically relevant injured heart group was outside the focus of this study, as scarring, inflammation, and morbidity potentially confound the principle assessment of electrical coupling capabilities of preconditioned SMs. However, disease-related aspects will have to be addressed further in vivo in future studies to assess the therapeutic potential of the approach presented here. Two aspects are important: on the one hand it is essential to confirm the long-term viability indicated in this study in conjunction with the functionality of the cells and link it to a potential therapeutic effect on the global heart function (eg, after MI). On the other hand, it will be necessary to address the feasibility of our approach in the context of extensive scarring and ischemia, because the isolating properties of scar tissues might render the use of epicardial transplantation ineffective.

Our results show that passive mechanical preconditioning enables SMs to couple electrophysiologically to myocardium in vivo after epicardial transplantation. This supports SMs as a promising option for the clinical application for cardiac cell therapy. However, further in vivo assessment will be necessary to optimize the routes of application and evaluate the therapeutic benefits.

\footnotetext{
References

1. Finegold JA, Asaria P, Francis DP. Mortality from ischaemic heart disease by country, region, and age: Statistics from World Health Organisation and United Nations. Int J Cardiol. 2013;168:934-45.

2. Beltrami AP, Urbanek K, Kajstura J, Yan SM, Finato N, Bussani R, et al. Evidence that human cardiac myocytes divide after myocardial infarction. N Engl J Med. 2001;344:1750-7.

3. Dimmeler S, Leri A. Aging and disease as modifiers of efficacy of cell therapy. Circ Res. 2008;102:1319-30.

4. Menasche P, Hagege AA, Vilquin J-T, Desnos M, Abergel E, Pouzet B, et al Autologous skeletal myoblast transplantation for severe postinfarction left ventricular dysfunction. J Am Coll Cardiol. 2003;41:1078-83.

5. Jennings RB, Reimer KA. Lethal myocardial ischemic injury. Am J Pathol. 1981 102:241-55
} 
6. Scorsin M, Hagege A, Vilquin JT, Fiszman M, Marotte F, Samuel JL, et al. Comparison of the effects of fetal cardiomyocyte and skeletal myoblast transplantation on postinfarction left ventricular function. J Thorac Cardiovasc Surg. 2000;119:1169-75.

7. Menasche P, Hagege AA, Scorsin M, Pouzet B, Desnos M, Duboc D, et al. Myoblast transplantation for heart failure. Lancet. 2001;357:279-80.

8. Steendijk P, Smits PC, Valgimigli M, van der Giessen WJ, Onderwater EE, Serruys PW. Intramyocardial injection of skeletal myoblasts: long-term follow-up with pressure-volume loops. Nat Clin Pract Cardiovasc Med. 2006; 3(Suppl 1):S94-100.

9. Siminiak T, Kalawski R, Fiszer D, Jerzykowska O, Rzezniczak J, Rozwadowska N, et al. Autologous skeletal myoblast transplantation for the treatment of postinfarction myocardial injury: phase I clinical study with 12 months of follow-up. Am Heart J. 2004;148:531-7.

10. Hagege AA, Marolleau J-P, Vilquin J-T, Alheritiere A, Peyrard S, Duboc D, et al. Skeletal myoblast transplantation in ischemic heart failure: long-term follow-up of the first phase I cohort of patients. Circulation. 2006;114:108-13.

11. Roell W, Lewalter T, Sasse P, Tallini YN, Choi B-R, Breitbach M, et al. Engraftment of connexin 43-expressing cells prevents post-infarct arrhythmia. Nature. 2007;450:819-24.

12. Suzuki K, Brand NJ, Allen S, Khan MA, Farrell AO, Murtuza B, et al. Overexpression of connexin 43 in skeletal myoblasts: relevance to cell transplantation to the heart. J Thorac Cardiovasc Surg. 2001;122:759-66.

13. Hofmann M, Wollert KC, Meyer GP, Menke A, Arseniev L, Hertenstein B, et al. Monitoring of bone marrow cell homing into the infarcted human myocardium. Circulation. 2005;111:2198-202.

14. Muller-Ehmsen J, Krausgrill B, Burst V, Schenk K, Neisen UC, Fries JW, et al. Effective engraftment but poor mid-term persistence of mononuclear and mesenchymal bone marrow cells in acute and chronic rat myocardial infarction. J Mol Cell Cardiol. 2006;41:876-84.

15. Hamdi H, Furuta A, Bellamy V, Bel A, Puymirat E, Peyrard S, et al. Cell delivery: intramyocardial injections or epicardial deposition? A head-to-head comparison. Ann Thorac Surg. 2009;87:1196-203.

16. Siepe M, Giraud MN, Pavlovic M, Receputo C, Beyersdorf F, Menasche P, et al. Myoblast-seeded biodegradable scaffolds to prevent post-myocardial infarction evolution toward heart failure. J Thorac Cardiovasc Surg. 2006;132: 124-31.

17. Christman KL, Lee RJ. Biomaterials for the treatment of myocardial infarction. $J$ Am Coll Cardiol. 2006;48:907-13.

18. Perumal Srinivasan S, Neef K, Treskes P, Liakopoulos OJ, Stamm C, Cowan DB, et al. Enhanced gap junction expression in myoblast-containing engineered tissue. Biochem Biophys Res Commun. 2012;422:462-8.

19. Neef K, Choi YH, Perumal Srinivasan S, Treskes P, Cowan DB, Stamm C, et al. Mechanical preconditioning enables electrophysiologic coupling of skeletal myoblast cells to myocardium. J Thorac Cardiovasc Surg. 2012;144: 1176-84.e1.
20. Halbach M, Pillekamp F, Brockmeier K, Hescheler J, Muller-Ehmsen J, Reppel M. Ventricular slices of adult mouse hearts-a new multicellular in vitro model for electrophysiological studies. Cell Physiol Biochem. 2006;18:1-8.

21. Choi YH, Stamm C, Hammer PE, Kwaku KF, Marler JJ, Friehs I, et al. Cardiac conduction through engineered tissue. Am J Pathol. 2006;169:72-85.

22. Drey F, Choi YH, Neef K, Ewert B, Tenbrock A, Treskes P, et al. Noninvasive in vivo tracking of mesenchymal stem cells and evaluation of cell therapeutic effects in a murine model using a clinical 3.0 T MRI. Cell Transplant. 2013; 22:1971-80.

23. Lambert JF, Benoit BO, Colvin GA, Carlson J, Delville Y, Quesenberry PJ. Quick sex determination of mouse fetuses. J Neurosci Methods. 2000;95: 127-32.

24. Li H, Choudhary SK, Milner DJ, Munir MI, Kuisk IR, Capetanaki Y. Inhibition of desmin expression blocks myoblast fusion and interferes with the myogenic regulators MyoD and myogenin. J Cell Biol. 1994;124:827-41.

25. Matsumura K, Tome FM, Collin H, Leturcq F, Jeanpierre M, Kaplan JC, et al. Expression of dystrophin-associated proteins in dystrophin-positive muscle fibers (revertants) in Duchenne muscular dystrophy. Neuromuscul Disord. 1994;4:115-20.

26. Gutstein DE, Morley GE, Tamaddon H, Vaidya D, Schneider MD, Chen J, et al. Conduction slowing and sudden arrhythmic death in mice with cardiac-restricted inactivation of connexin 43. Circ Res. 2001;88:333-9.

27. Fromaget C, el Aoumari A, Gros D. Distribution pattern of connexin 43, a gap junctional protein, during the differentiation of mouse heart myocytes. Differentiation. 1992;51:9-20.

28. Davis LM, Saffitz JE, Beyer EC. Modulation of connexin 43 expression: effects on cellular coupling. J Cardiovasc Electrophysiol. 1995;6:103-14.

29. Gepstein L, Ding C, Rahmutula D, Wilson EE, Yankelson L, Caspi O, et al. In vivo assessment of the electrophysiological integration and arrhythmogenic risk of myocardial cell transplantation strategies. Stem Cells. 2010;28: 2151-61.

30. Chang MG, Tung L, Sekar RB, Chang CY, Cysyk J, Dong P, et al. Proarrhythmic potential of mesenchymal stem cell transplantation revealed in an in vitro coculture model. Circulation. 2006;113:1832-41.

31. Halbach M, Pfannkuche K, Pillekamp F, Ziomka A, Hannes T, Reppel M, et al. Electrophysiological maturation and integration of murine fetal cardiomyocytes after transplantation. Circ Res. 2007;101:484-92.

32. Kramer K, van Acker SA, Voss HP, Grimbergen JA, van der Vijgh WJ, Bast A. Use of telemetry to record electrocardiogram and heart rate in freely moving mice. J Pharmacol Toxicol Methods. 1993;30:209-15.

33. Takens-Kwak BR, Jongsma HJ, Rook MB, Van Ginneken AC. Mechanism of heptanol-induced uncoupling of cardiac gap junctions: a perforated patch-clamp study. Am J Physiol. 1992;262:C1531-8.

34. Fernandes S, van Rijen HV, Forest V, Evain S, Leblond AL, Merot J, et al. Cardiac cell therapy: overexpression of connexin 43 in skeletal myoblasts and prevention of ventricular arrhythmias. J Cell Mol Med. 2009;13:3703-12. 